\title{
An Innovative English Teaching Mode Based on Massive Open Online Course and Google Collaboration Platform
}

\author{
https://doi.org/10.3991/ijet.v14i15.11148 \\ Xiufang Liang $(\varpi)$ \\ Cangzhou Normal University, Cangzhou, China \\ Liangxf@ $126 . \mathrm{com}$ \\ Jin Pang \\ Hebei University of Water Resources and Electric Engineering, Cangzhou, China
}

\begin{abstract}
The web-based collaborative teaching mode is the key to reforming the teaching mode and developing the teaching practice. To improve the traditional English teaching mode, this paper puts forward an innovative English teaching method for elementary, secondary and higher education based on the massive open online course (MOOC) and Google Collaboration platform. The research shows that it is possible for students to learn collaboratively under the guidance of teachers; the students can broaden their horizon by searching for more materials on the online collaboration platform, according to the objectives and themes laid down by the teachers; the proposed innovative English teaching method can improve the learning efficiency of the students, encourage them to participate in learning and collaboration, arouse their interest and enthusiasm in foreign language learning, and help them to gain insights into learning. The research findings provide technical support to the reform and innovation of English teaching mode, and lays a theoretical basis for deepening the reform of teaching methods in various disciplines.
\end{abstract}

Keywords-Massive open online course (MOOC), google collaboration platform, English teaching, teaching mode innovation

\section{Introduction}

Today, with the rapid development of the network and social economy, the demand for high-quality talents in the social environment has increased year by year. However, there still exist some problems in the teaching mode of elementary and secondary schools, even in colleges and universities; they cannot fully utilize the existing teaching resources to promote the all-round development of students. In recent years, as new technologies and new web application systems emerge continuously, they have been applied and improved in all areas of our living environment [1-12]. Meanwhile, the application of the network in the field of education has gradually expanded and began to be applied in teaching, which has subverted the traditional face-to-face teaching mode [13-14]. 
Web-based collaborative learning is a learning method that combines network resources with traditional learning methods. With the advent of the web2.0 era, the advantages of web-based collaborative learning have become more prominent, and it is of great significance for improving students' learning methods, collaboration ability among students, and innovation capabilities [15-16]. This new type of learning has greatly inspired the reform of the current teaching model by combining the web-based collaborative learning model with the traditional face-to-face teaching method, which can improve the teaching environment from many aspects, stimulate students' interest in learning, and promote their learning efficiency [17-18]. Therefore, the web-based collaborative teaching mode has important theoretical significance for the improvement of individual ability and social progress.

In the today's social context of network environment and teaching needs, many online learning platforms and communication platforms have emerged successively, such as Google Collaborative Platform, Massive Open Online Courses (MOOCs), and Xiaomuchong academic and research forum (xmuchong. Com) etc. [19]. Google is one of the rapidly growing Internet giants in the 21 st century, to provide cloud services for online users. Its Google Scholar, Google Earth and Google Maps have been widely used around the world, bringing great convenience for people's life, study and work [20-22]. The MOOC online learning platform is a network platform with largescale online open courses based on networked learning, which also broadens the learning channels of students at all stages. But the operation of these platforms requires a lot of professional and resources, making it difficult to open and operate in schools [23-24].

In order to make full use of the advanced network platform, this paper takes English teaching innovation as an example, and puts forward an innovative English teaching mode based on Google collaboration platform and MOOC platform to provide students with a new type of convenient, comprehensive and efficient learning channels. This study shall lay the foundation for promoting the education reform and teaching informationization.

\section{Relevant Innovation Theories of English Teaching Collaboration Platform}

\subsection{Web-based collaborative learning}

Intuitively, web-based collaborative learning is to conduct online learning through network resources. To be specific, by means of the network technology and resources, it uses the virtual network platform to create a virtual teaching environment, and sets up a modular learning group for on-line exchange, learning, and discussion among students, which expands the learning scope and communicating groups, better promotes the learning effect, and enables students to achieve their learning goals.

At present, the main issue for the students is the way of learning in case of problems, as shown in Fig 1. The students using the network query method to solve problems occupies a relatively small proportion. Compared with traditional face-to-face 
learning, web-based collaborative learning has more advantages, such as stronger shareability, timeliness and personalization. Besides, the web-based collaborative learning is not limited by space; learning time can also be chosen independently; the relevant information can be published on the website; the content of the learning can be presented in the form of e-mail, MSN, Google, etc; the final learning outcomes can be displayed in various forms, such as PPT, sound, audio, etc.

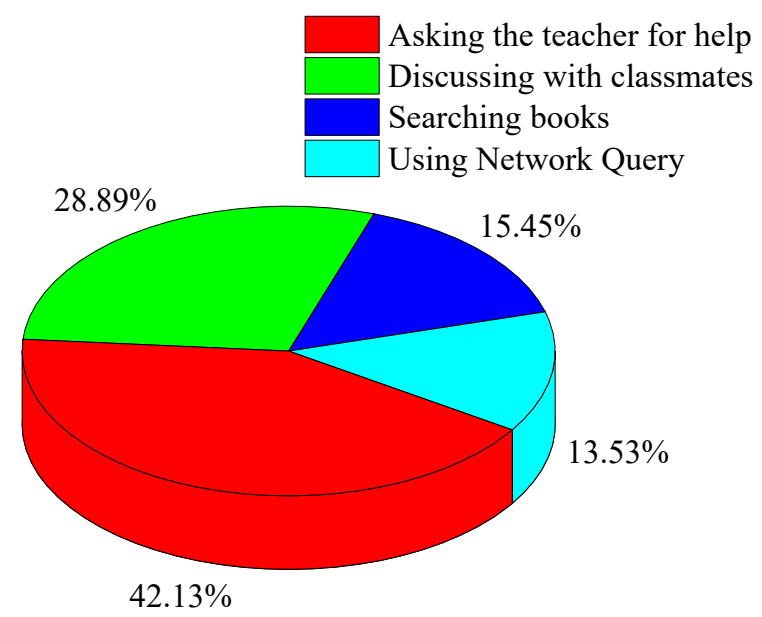

Fig. 1. Student's learning model in the case of problems

\subsection{Theoretical basis and key features of the MOOC}

MOOC is a new type of online teaching mode that is accompanied by the development of information technology. Fig 2 shows the MOOC webpage.

The main theoretical foundations of MOOCs include mastery learning theory, constructivist learning theory and achievement motivation theory. In the mastery learning theory, the corresponding exercises and exam questions are designed so that the students can practice independently after class, check and fill in the gaps in time for improving their learning efficiency; constructivist learning theory is an important guide to the promotion and popularization of MOOC teaching, allowing the students to learn independently, and actively seek resources to solve problems, and MOOC also integrates the scenes in life, better helping students to understand and learn knowledge through a variety of forms; the theory of achievement motivation is to mobilize students' interest, let students to learn initiatively and choose courses according to their own interests and hobbies, and MOOCs also give students corresponding rewards, or issue a certificate of completion. 


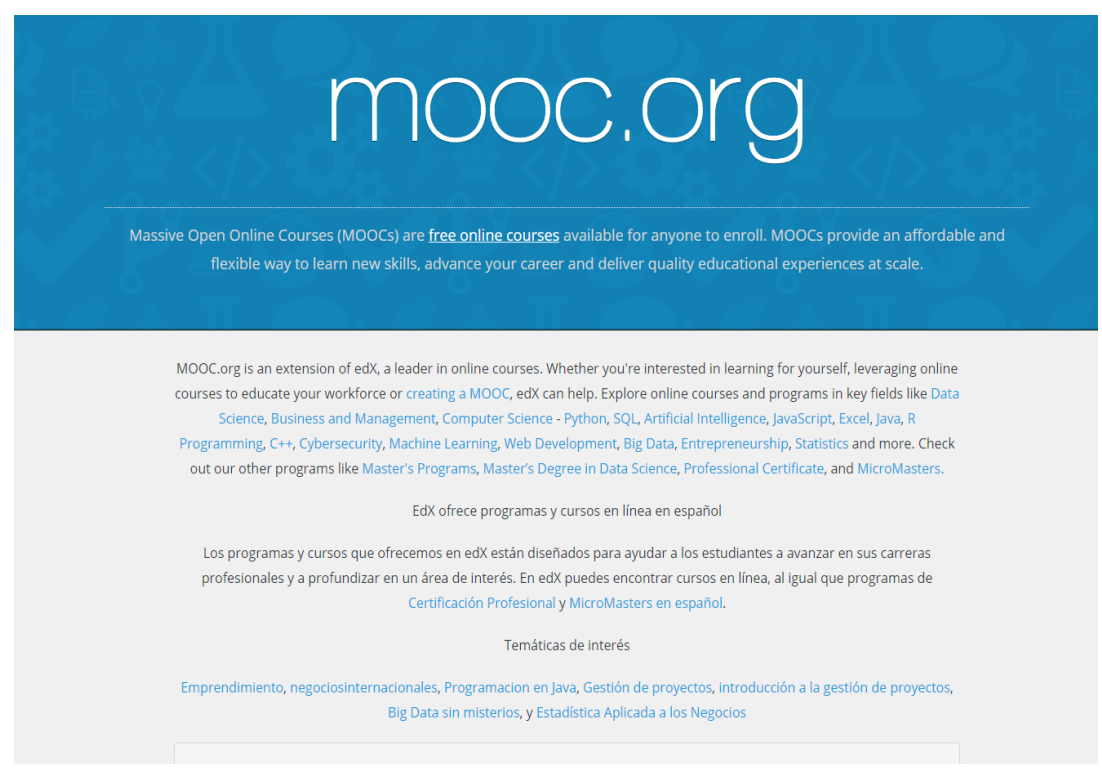

Fig. 2. Webpage of MOOCs

The key features of the MOOC are massiveness, open access, and flexible curriculum design. MOOC integrates the quality courses from many universities around the world, and the number of users is very huge. Open learning is not only reflected in online listening, but also users' questions about the course which can be published in the community; besides the lecturer, others can also answer questions online to achieve mutual benefit and win-win results; the curriculum is set according to people's memory habits, that is, each lesson is set to 15 minutes or so, and 1 and 2 knowledge points are taught intensively, to improve students' learning efficiency.

\subsection{Theoretical basis of the Google collaborative platform}

Google has developed a series of products such as Google Calendar, Google Docs, Gmail, and Google Group etc., which cover a wide range of functions. Most services provided by Google have the advantages of free-of-charge, high compatibility, easy operation, good sharing, and complete access. They can provide technical support and more resources for e-learning. The main features and functions of Google collaboration platform are: providing convenience for learners, achieving the common construction and sharing of learning resources, making evaluation and self-evaluation of students' learning process. 


\section{Establishment of English Teaching Mode Based on MOOC and Google Collaboration Platform}

\subsection{Principles for establishing a collaborative English teaching mode}

The principle of constructing the English teaching mode is to integrate the respective advantages of the MOOC and Google for better serving the learners. This mode can better promote communication, learning and collaboration, and can quickly utilize the platform for resource integration and resource sharing. In the process of resource integration, MOOC and Google's accounts should be mutually connected so that the learner can automatically log in to another platform for reliable assistance.

\subsection{Establishment of collaborative English teaching mode}

The English teaching mode based on MOOC and Google collaboration platform mainly includes guiding ideology, teaching objectives, teacher-student relationship and teaching procedures. First of all, it's necessary to make full use of Google tools for establishing a convenient, practical and scientific online collaborative English learning mode. Secondly, students should be required to master new learning tools and experience the advantages of new collaborative platforms so that they will actively learn and use. Finally, students are free to team up for collaborative learning, and teachers provide guidance for students' learning.

Fig 3 shows the flow of the web-based collaborative English teaching application model. The collaborative English teaching process is divided into four steps: First, be familiar with the MOOC and Google collaboration and build an English teaching platform; students need to enter the website and apply for a private account, choose the courses and content they need to learn, get familiar with the basic operations and build a personal English learning platform. Second, identify the topic and create the team; based on the teaching objectives and content, the teacher determines the scope of the topic, collects relevant resources and books, confirms the final theme, and clarifies the requirements and goals, while the learners are grouped by teachers according to their own characteristics, each group of 3-5 people, and the members of the study group need to build trust, actively participate and reach an agreement. Third, carry out the study group. The group will obtain relevant materials through the MOOC and Google platform, and discuss it; teachers can evaluate the group's learning in the background, and provide guidance and suggestions for the team's presentation results, while the group members adjust and improve the work according to teachers' evaluation. Fourth, make the result show and evaluation. The final results of the group are comprehensively evaluated through student self-assessment, group review and teacher evaluation to stimulate students' enthusiasm and initiative. The time management module in MOOC and google collaboration platform can help students manage all the learning tasks, remind students of the learning activities, allow them to learn more effectively, push the relevant courses that students are interested about, and remind students to learn independently. Throughout the online learning process, they can 
accumulate and reflect on the learning curriculum, and continuously improve our own deficiencies to achieve self-education.

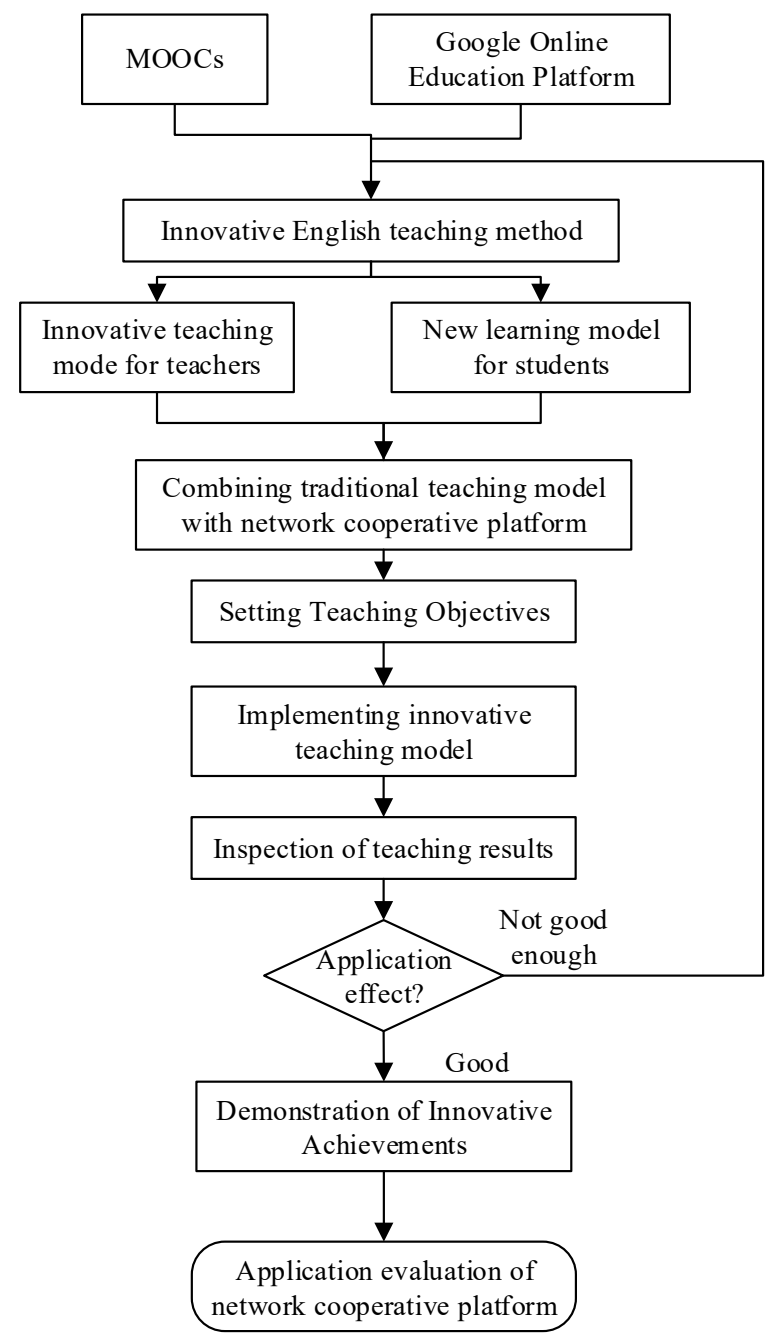

Fig. 3. Creation process of innovative cooperative platform for English teaching

\subsection{Practice and evaluation of English teaching collaboration platform}

70 students were taught using the new teaching platform based on MOOC online education and google collaboration platform, and the learning objectives were specified. Through the English teaching collaboration platform, students had a personal experience of the new teaching methods, and also learned how to conduct collaborative learning. In order to know about the students' understanding and use of the English teaching collaboration platform, the effectiveness of the English learning, and the 
students' interaction during the use process, a questionnaire was made and the survey results were also analysed.

Fig 4 shows the students' use of the English collaboration platform. It can be seen that more than $3 \%$ of the students use it frequently, about $40 \%$ of the students use less frequently, and about $30 \%$ of the students have never used, indicating that the overall use of the English collaboration platform is low.

Fig 5 shows the survey results of students' attitude towards the learning model of the web-based collaboration platform. It can be seen from the figure that $87 \%$ of the students are satisfied with the learning model using the web-based collaboration platform in the English teaching process, $8.5 \%$ of the students are somewhat dissatisfied, and only $4.5 \%$ of the students aren't satisfied. This indicates that most students acknowledge the effect of this teaching method based on web-based collaboration platform.

According to the survey results in Fig 6, 77.7\% of the students believe that the web-based collaborative teaching mode has help for their English learning to varying degree; $14.9 \%$ of the students think that they are not helpful; $7.4 \%$ of the students think the innovative method has a negative effect on improving their English. On the whole, most students think that English collaboration platform can improve their English level, and they are willing to accept new teaching methods; effective use of network resources can fill their own knowledge gaps, and improve their own network knowledge management capabilities.

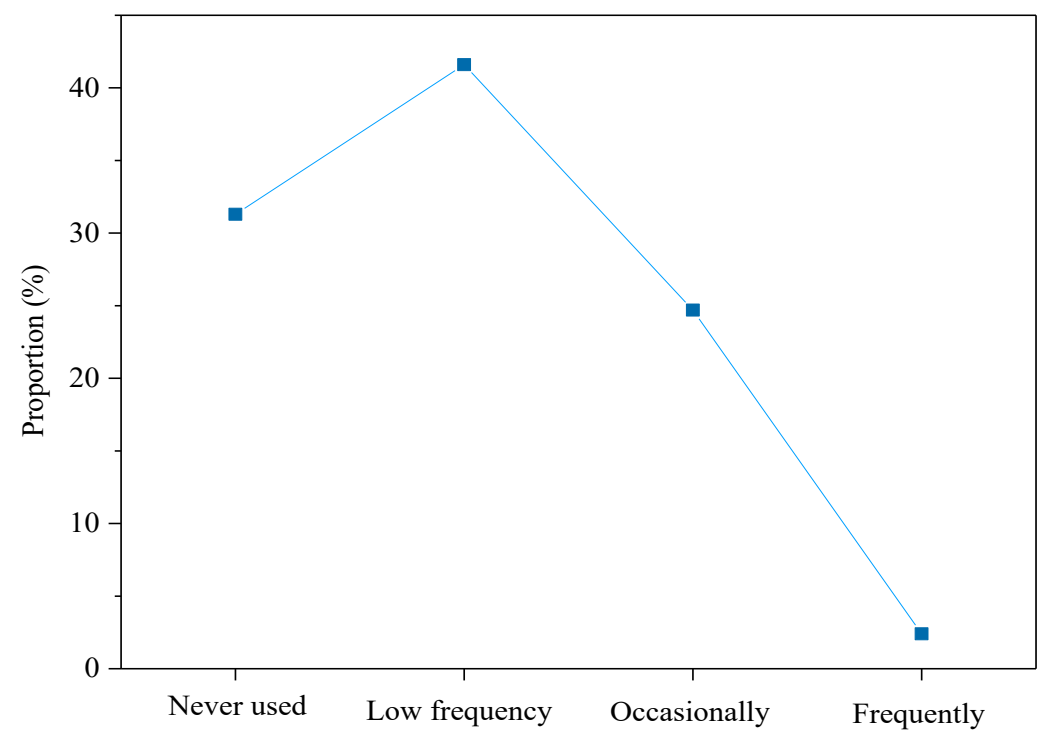

Fig. 4. Frequency of learning by using Google 


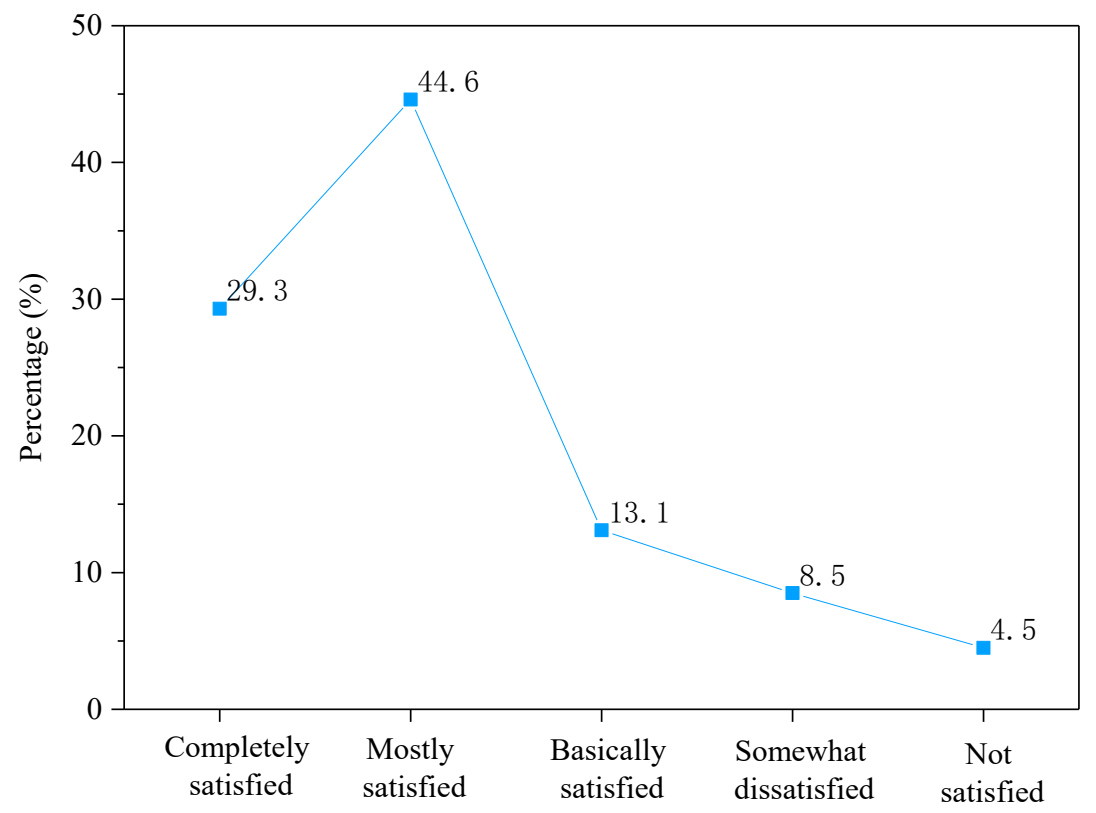

Fig. 5. Students' degree of satisfaction with innovative approaches to English teaching

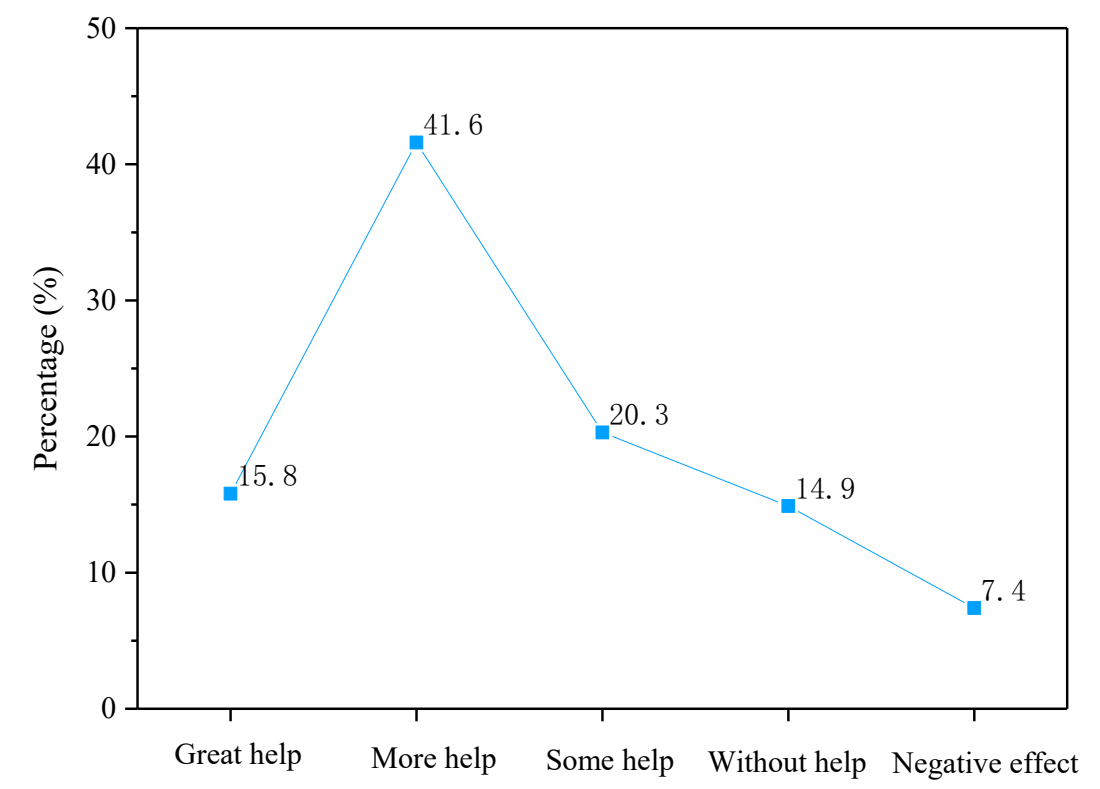

Fig. 6. The help degree of innovative teaching methods in teaching English to students 


\section{Conclusion}

Online education platform or web-based learning platform has emerged in recent years, but the web-based collaborative teaching has been rarely applied in all levels of schools. For this, the paper applies the web-based learning to English teaching and learning, and establishes a new type of web-based collaborative teaching mode based on MOOCs online education and Google collaboration platform. The main conclusions are as follows:

- Combined with the traditional teaching method, the innovative English teaching method can significantly stimulate the enthusiasm of learners in learning and collaboration, improve students' efficiency in the English learning process, and help them to understand the knowledge in a deeper level.

- Web-based collaborative English teaching can enhance students' collaboration ability, promote their sense of accomplishment in the learning process, and then cultivate their interest and enthusiasm in foreign language learning.

- The survey results show that more than $85 \%$ of students believe that the web-based collaboration platform can improve their English ability and give great helps for English learning.

\section{$5 \quad$ References}

[1] Clarà, M., Barberà, E. (2013). Learning online: massive open online courses (MOOCs), connectivism, and cultural psychology. Distance Education, 34(1): 129-136. https://doi.org/10.1080/01587919.2013.770428

[2] Kang, Z., He, L. (2018). Construction and practice of SPOC teaching mode based on MOOC, International Journal of Emerging Technologies in Learning, 13(12): 35-49. http://doi.org/10.3991/ijet.v13i12.9702

[3] Wakil, K., Jawawi, D. N. A. (2017). Increasing usability for web engineering methods. Review of Computer Engineering Studies, 4(3), 93-97. https://doi.org/10.18280/ rces.040302

[4] Raad, J., Beek, W., Pernelle, N., Saïs, F., Van Harmelen, F. (2018). Detection of false identity links using community detection in identity graphs. Ingénierie des Systèmes d'Information, 23(3-4), 95-118. https://doi.org/10.3166/ISI.23.3-4.95-118. https://doi.org/ 10.3166/isi.23.3-4.61-88

[5] Beretta, V., Ranwez, S., Harispe, S., Mougenot, I. (2018). Benefit from domain ontologies and rule mining to improve truth discovery. Revue d'Intelligence Artificielle, 32(3), 373405. https://doi.org/10.3166/RIA.32.373-405

[6] Gandon, F. (2018). A survey of the first 20 years of research on semantic web and linked data. Ingénierie des Systèmes d'Information, 23(3-4), 11-56. https://doi.org/10.3166/ISI. 23.3-4.11-56. https://doi.org/10.3166/isi.23.3-4.11-38

[7] Tan, Z. F., Deng, R., Wei, X. F., Yu, C. H. (2018). An integrated MAC protocol based on DMAC for emergency priority. Review of Computer Engineering Studies, 5(4), 65-70. https://doi.org/10.18280/rces.050402 
[8] Taj, S., Asad, U., Azhar, M., Kausar, S. (2018). Interoperability in IOT based smart home: A review. Review of Computer Engineering Studies, 5(3), 50-55. https://doi.org/10. $\underline{18280 / \text { rces. } 050302}$

[9] Dong, T., Lamolle, M., Le Duc, C., Bonnot, P. (2018). Moteur de révision d'ontologie en SHIQ. Ingénierie des Systèmes d'Information, 23(2), 39-59. https://doi.org/10.3166/isi. 23.2.39-59

[10] Guo, Q., Zou, G. T., Sun, T. Z. (2018). Discovery of the knowledge on the demands of building users based on extension clustering. Revue d'Intelligence Artificielle, 32(5-6), 705-718. https://doi.org/10.3166/ria.32.705-718

[11] Chamberlin, L., Parish, T. (2011). Moocs: Massive open online courses or massive and often obtuse courses. eLearn, (8). http://doi.org/10.1145/2016016.2016017

[12] Lopez, C., Dhouib, M. T., Cabrio, E., Zucker, C. F., Gandon, F., Segond, F. (2018). SMILK, linking natural language and data from the web. Revue d'Intelligence Artificielle, 32(3), 287-312. https://doi.org/10.3166/RIA.32.287-312

[13] Murphy, K., Munk P. L. (2013). Continuing medical education: MOOCs (massive open online courses) and their implications for radiology learning. Canadian Association of Radiologists Journal, 64(3): 165. http://doi.org/10.1016/j.carj.2013.06.001

[14] Beltrán, C., \& Rubén. (2014). Massive online open courses and language learning: the case for a beginners' English course. Procedia - Social and Behavioral Sciences, 141: 242-246. http://dx.doi.org/10.1016/j.sbspro.2014.05.042

[15] Sevilla-Pavón, A. (2016). Affordances of telecollaboration tools for english for specific purposes online learning. World Journal on Educational Technology Current Issues, 8(3). http://doi.org/10.18844/wjet.v8i3.696

[16] Yang, D., Wen, M., Kumar, A., Xing, E. P., Carolyn, Penstein, R. (2014). Towards an integration of text and graph clustering methods as a lens for studying social interaction in MOOCs. International Review of Research in Open \& Distance Learning, 15(5): 214-234. http://doi.org/10.19173/irrodl.v15i5.1853

[17] Brigo F., Igwe, S. C., Ausserer H., Nardone, R., Tezzon, F., Bongiovanni, L. G., Trinka, E. (2014). Why do people google epilepsy? An infodemiological study of online behavior for epilepsy-related search terms. Epilepsy \& Behavior, 31(2): 67-70. http://doi.org/10.1016/j. yebeh.2013.11.020

[18] Guo, X. (2016). Action research on college English writing based on information technology from the perspective of MOOCs. English Language Teaching, 9(11): 48. http://doi.org/10.5539/elt.v9n11p48

[19] Chen, J. (2017). An e-portfolio-based model for the application and sharing of college English ESP MOOCs. Higher Education Studies, 7(2): 35. http://doi.org/10.5539/hes.v 7n2p35

[20] Colas, J. F., Sloep, P. B., Garretadomingo, M. (2016). The effect of multilingual facilitation on active participation in MOOCs. International Review of Research in Open \& Distance Learning, 17(4). http://doi.org/10.19173/irrodl.v17i4.2470

[21] Lentell, H. (2014). Invasion of the MOOCs: the promise and perils of massive open and online courses. Open Learning, 29(3): 256-258. http://doi.org/10.1080/02680513.2015.10 $\underline{11113}$

[22] Evans, B. J., Baker, R. B., Dee, T. S. (2016). Persistence patterns in massive open online courses (MOOCs). Journal of Higher Education, 87(2): 206-242. http://doi.org/10.1080/00 221546.2016 .11777400

[23] Abeywardena, I. S. (2013). OERScout technology framework: a novel approach to open educational resources search. International Review of Research in Open \& Distance Learning, 14(4): 214-237. http://doi.org/10.19173/irrodl.v14i4.1505 
[24] Ventura, P., Bárcena, E., Martín-Monje, E. (2014). Analysis of the impact of social feedback on written production and student engagement in language MOOCs. Procedia - Social and Behavioral Sciences, 141: 512-517. http://doi.org/10.1016/j.sbspro.2014.05.089

\section{Authors}

Xiufang Liang was born in Hebei province in 1981, Master of Arts, Lecturer. She graduated from Yanshan University in 2008 and worked in Cangzhou Normal University from 2009. She is the Dean of Basic English Education Office. Her research interests include English Teaching and Intercultural Communication. In the process of her teaching career, she teaches Intensive Reading, English Writing,College English and Commercial English. She had published several related thesis on English teaching. She also publish a book concerning Commercial English Translation in the year 2017. She took part in the English Teaching Contest, the third prize. She holds the municipal project and finishes the project successfully. In 2017, she holds the research project of Hebei Education Department. In the following year, she takes part in another two research projects of Hebei Education Department and Hebei Social Science Federation. In the following years, she will try to conduct researches on other related fields of English.

Jin Pang was born in Hebei province in 1981, Master of Arts, Lecturer. He graduated from Yanshan University in 2009 and worked in Hebei University of Water Resources and Electric Engineering from 2009. He is the deputy secretary of College of computer and information engineering. His research interests include Ideological and Political Education and Intercultural Communication. In the process of his teaching career, he teaches College English and Career Planning for College Students. He had published several related thesis on Ideological and Political Education and Career Planning for College Students. He also publishes a book concerning Commercial English Translation in the year 2017. He takes part in the English Teaching Contest and Career Planning Contests, the third prize and the second prize respectively. He holds the municipal project and finishes the project successfully. In 2017, he takes part in the research project of Hebei Education Department. In the following year, he takes part in another two research projects of Hebei Education Department and Hebei Social Science Federation. In the following years, he will try to conduct researches on other related fields.

Article submitted 2019-05-29. Resubmitted 2019-07-03. Final acceptance 2019-07-04. Final version published as submitted by the authors. 